\title{
Effect of Aegle marmelos on the growth of brushite crystals
}

\author{
G. Anushya ${ }^{1 *}$ D, R. Mahesh² ${ }^{2}$ T. H. Freeda ${ }^{1}$, R. Ramachandran ${ }^{3}$ and G. Raju ${ }^{4}$
}

\begin{abstract}
Background: The urinary stone formation is a very common health problem due to the prolonged medication. Calcium Hydrogen Phosphate Dihydrate $\left(\mathrm{CaHPO}_{4} \cdot 2 \mathrm{H}_{2} \mathrm{O}, \mathrm{CHPD}\right.$ and Brushite) is one of the major constituent of urinary stone crystals. The formation and deposition of brushite crystals is the central cause of recurrent kidney stone disease among the global population. The present study aims to investigate the effect of Aegle marmelos leaves on the growth of brushite crystals to explicate the inhibitory effect of urinary stones from a different point of view.

Methods: The CHPD crystals were grown by the Single Diffusion Gel growth technique. In order to inhibit the formation of urinary stones, CHPD crystals are grown in the laboratory in the pure form and by adding the prolonged medicine A. marmelos taken especially by diabetic patients. A comparative study of the pure and A. marmelos leaves added crystals has been carried out using the Growth factor, Powder X-ray diffraction, Microstructural parameters, FTIR and SEM-EDAX.
\end{abstract}

Results: Total mass of the grown crystals is found to decrease with increasing concentrations of leaf extract of the $A$. marmelos. On comparing with undoped, crystalline size of the A. marmelos doped samples is reduced. Disappearance of absorption band and peak shift in the FTIR shows the incorporation of functional groups of $A$. marmelos. The morphology changes of the treated crystals are assessed in SEM.

Conclusions: The result shows that herbal extracts prepared from A. marmelos have good inhibitory effect on the growth of the brushite urinary stone crystals considered.

Keywords: Brushite, Aegle marmelos, Gel growth, X-ray diffraction, Microstructural parameters

\section{Introduction}

Nephrolithiasis is a common health issue that affects at least once in a lifetime between 2 and $5 \%$ of the population worldwide. Because of this condition, the prevalence of urinary stones is increasing and about 12,000 patients are hospitalized each year. Many risk factors have been associated with this debilitating and costly illness including geographical [1] and weather conditions [2] physical traits [3] nutritional issues [4] and more recently, metabolic syndrome [5] are some of the causes of an increased risk of kidney stones. Approximately $85 \%$ of kidney stones are calcium stones [6] in combination with

\footnotetext{
* Correspondence: g.anushya7@gmail.com

${ }^{1}$ Physics Research Centre, S.T. Hindu College, Nagercoil, Tamil Nadu 629 002, India

Full list of author information is available at the end of the article
}

either oxalate or phosphate, or both in the form of apatite or brushite [7]. The first stage of kidney stone includes the nucleation, growth and accumulation of crystals. In the second stage, the crystals are remained in the kidneys and/or renal tubules, and eventually they move from the interior part of the kidney to the papillary surface of the kidney to form a stone nidus. Minerals especially calcium in the urine, then develop on the speck in a similar manner to that in which a pearl grows in an oyster shell. The formation of the nidus may be analogous to the first stage in the physiological calcification of the bone in which the calcium phosphate nucleus develops in the organic matrix $[8,9]$. It is reported that calcium phosphate is the major solute component which crystallize rapidly in urine. Its presence is also reported in small quantities in renal and urethral stones [10]. 
Moreover, small amounts of calcium phosphate have been found in the assumed binding portion of the stone [11]. These observations suggest that other stones originate from the precipitation of calcium phosphate and that the renal papilla is bound to the early stages of these stones. Once a crystal nidus has been established, it develops into a kidney stone by precipitation or by the process of crystal growth. Initially, kidney stones often have no symptoms. The first symptom of kidney stone is extreme pain as stones block the flow of urine [12].

Calcium Hydrogen Phosphate Dihydrate (CHPD, Brushite, and $\mathrm{CaHPO}_{4} \cdot 2 \mathrm{H}_{2} \mathrm{O}$ ) plays a major role in the urinary calculi formation. Calcium phosphate stone formation is related to conditions such as hyperparathyroidism [13] and renal tubular acidosis [14]. Brushite is a unique form of $\mathrm{CaP}$ that can form large symptomatic stones in certain patients. The molecular structure of brushite is shown in Fig. 1. It can be difficult to treat brushite stones as they are resistant to shock waves and ultrasonic lithotripsy and also require ballistic fragmentation. Patients with brushite stone disease are less likely to become stone free after surgery and often experience repetition in the stone despite maximum medical intervention [16]. In order to evaluate the transportation of renal phosphate, Dhayat et al. [17] used the ratio of tubular maximum reabsorption of phosphate to glomerular filtration rate (TmP/GFR) showing that low $\mathrm{TmP} /$ GFR is correlated with increased excretion of calcium in the urine and increased prevalence of brushite stones. Xie et al. [18] showed that ACP plays a vital role in nucleating calcium oxalate stones by promoting the accumulation of amorphous calcium oxalate (ACO) precursors at early induction stages. As compared to other stones, phosphate stones were high in magnesium,

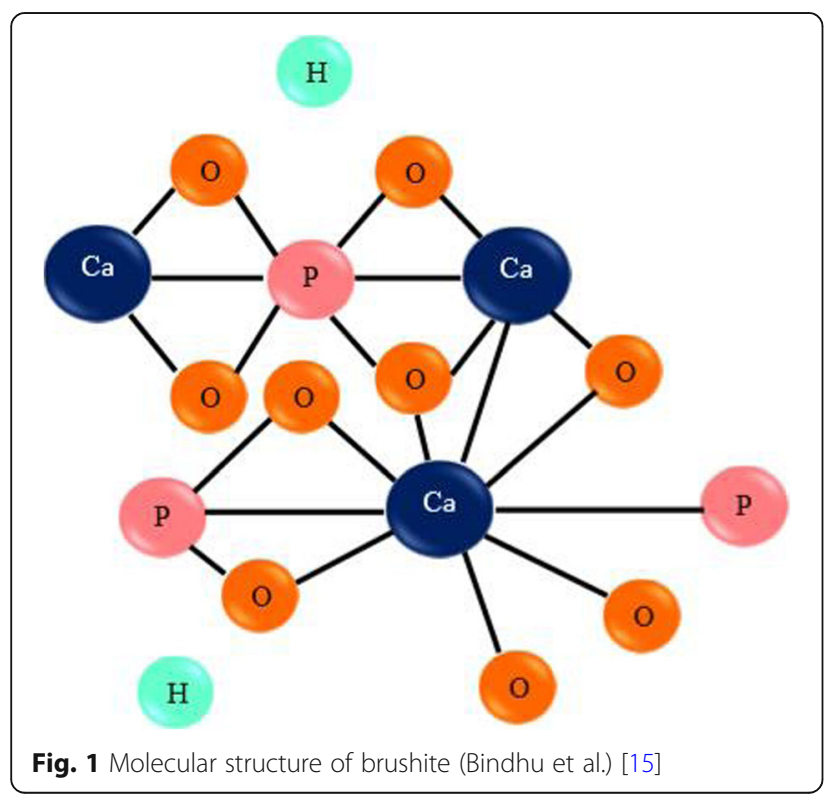

strontium, zinc and chromium [19]. Moreira et al. [20] reported that the brushite stones were associated with higher urinary calcium excretion and higher urinary supersaturation $\mathrm{CaP}$ when compared to apatite stones. Aggressive measures to reduce urinary calcium can be especially helpful in preventing brushite stone formation.

When any patient takes any drugs constantly and continuously, it ends up with some side effects. In some cases, the intake of drugs changes the biochemistry of the urine and it may induce the crystallization of metabolic compounds of unusual morphology, which indicates the possibility that there are peculiar conditions for the formation of urinary stones. In order to find out the formation of urinary stones as being the unwanted effect of the intake of diabetic medicines, the present work is carried out. In this study, the A. marmelos is taken for consideration. A. marmelos, known as Bael in India, is a famous Rutaceae plant, one of Ayurveda's most important plants [21]. Different parts of this plant, such as leaves, roots, seed, bark and fruit are used by the Ayurvedic practitioners due to its various medicinal properties [22, 23]. Traditionally, fever, diabetes, diarrhea, abscesses and snake bites have been treated with the plant $[24,25]$. Moreover, extracts of A. marmelos have good anti-diabetic properties [26]. Although several studies have been carried out with this plant, there is no documentation for the effect of diabetic drug $A$. marmelos on urinary stones. Hence, the present study is intended to investigate the effect of $A$. marmelos leaves on urinary stone formation.

\section{Experimental \\ Chemicals}

Sodium Meta Silicate (SMS) - $\left\{\mathrm{Na}_{2} \mathrm{SiO}_{3} .9 \mathrm{H}_{2} \mathrm{O}\right\}$ and Calcium Acetate $\left(\mathrm{Ca}\left(\mathrm{C}_{2} \mathrm{H}_{3} \mathrm{O}_{2}\right)_{2}\right)$ have been purchased from Loboma chemicals Ltd. All other chemicals such as Calcium Chloride $\left(\mathrm{CaCl}_{2}\right)$ and Orthophosphoric acid $\left(\mathrm{H}_{3} \mathrm{PO}_{4}\right)$ have been purchased from Merck (Mumbai, India). All the chemicals are of analytical grade and are used without any further purification or post-treatment. Double distilled water is used for cleaning the glass wares.

\section{Plant materials and identification}

Fresh leaves of $A$. marmelos were collected from the natural surroundings and authenticated at the Department of Botany, S.T. Hindu College, Nagercoil, Tamil Nadu, India. The collected leaves were washed with double distilled water followed by shade drying. The dried leaves were grounded into a fine powder and used for further experiments.

\section{Growth of brushite crystals}

The single diffusion gel growth method is employed to study the growth and inhibiting behavior of brushite 
crystals using A. marmelos [27, 28]. For crystallization, glass test tubes of size $140 \mathrm{~mm}$ length and $25 \mathrm{~mm}$ in diameter are used in this method. Sodium meta-silicate solution of specific gravity $1.03 \mathrm{~g} / \mathrm{cc}$ has been impregnated with orthophosphoric acid according to the desired $\mathrm{pH}$ value. The solutions $\mathrm{pH}$ value is set to 6.5 . The time required to set the gel firmly was dependent on $\mathrm{pH}$ value of the mixture. Within $48 \mathrm{~h}$, good quality gels were set in the test tubes for the $\mathrm{pH}$ value chosen above. Once when the solution undergoes a gelation phase, an aqueous solution of calcium chloride and calcium acetate of a specific molarity was carefully poured over the gel using pipette to prevent any breakage of the gel. The test tubes were capped with airtight stopples after pouring supernatant solution. The following reaction is expected to take place leading to the formation of calcium hydrogen phosphate dihydrate crystals.

$\mathrm{CaCl}_{2} \cdot 2 \mathrm{H}_{2} \mathrm{O}+\mathrm{CaC}_{4} \mathrm{H}_{6} \mathrm{O}_{4}+\mathrm{H}_{3} \mathrm{PO}_{4} \rightarrow \mathrm{CaHPO}_{4} \cdot 2 \mathrm{H}_{2} \mathrm{O}+\mathrm{CaCO}_{3}+\mathrm{HCl}$

To study the effect of $A$. marmelos leaf extract on the growth of brushite crystals, the following method was used. The finely powdered leaf extracts of different concentrations $(10 \mathrm{mg}$ to $50 \mathrm{mg}$ ) were separately added along with calcium chloride and calcium acetate and the crystals are grown as before. The $\mathrm{Ca}^{2+}$ ions and additional ions available in the $A$. marmelos extract are diffused into the gel and react with the phosphate ions in the gel column. This reaction leads to the formation of medicines added calcium hydrogen phosphate dihydrate crystals thereby showing its promotery or inhibitory effect on these crystals. The above experiment was conducted simultaneously with the control system to compare the growth and morphology of the undoped CHPD and A. marmelos doped CHPD crystals.

The formation of Liesegang rings followed by subsequent crystallization and aggregation of CHPD crystals were noted. In about 25 days, the crystal growth was completed. The grown crystals removed and collected carefully in a clean petri dish and then harvested using distilled water to remove the gel. Then the harvested crystals are dried by placing them at room temperature in a filter paper. The dried crystals are finely powdered and used for further characterization.

\section{Characterization techniques}

\section{Powder X-ray diffraction}

Powder X-ray diffraction (PXRD) is used to identify the crystal structure and collected on a XPERT-PRO diffractometer with $\mathrm{CuK \alpha}$ radiation $(\lambda=1.54060 \AA)$ over a range of $10-80^{\circ}$ in 0.05 step sizes with an integration time of $10 \mathrm{~s}$.

\section{Fourier transform infrared spectroscopy}

The FTIR spectra were recorded in Shimadzu - FTIR $8400 \mathrm{~S}$ with Spectral range: $4000-400 \mathrm{~cm}^{-1}$ and Resolution: $4 \mathrm{~cm}^{-1}$ with $\mathrm{KBr}$ beam splitter and DLATGS Detector.

\section{Scanning Electron microscopy (SEM) and energy dispersive $X$-ray analysis (EDAX)}

The surface features of the crystals are studied using Scanning Electron Microscope (SEM Model ZEISS EVO 18). EDAX is recorded using dispersive spectrometer (AMETEK EDAX) attached to the scanning electron microscope for carrying out elemental analysis of the crystals.

\section{Results and discussion Growth kinetics}

The silica gel is set and $1.5 \mathrm{M}$ concentration of calcium chloride and calcium acetate was poured on it, while we understand the growth mechanism, it is found that the $\mathrm{Ca}^{2+}$ ions diffuse through the gel column and immediately react with phosphate and precipitated forming Liesegang rings in just $4-5 \mathrm{~h}$. The number of Liesegang rings gradually increase with time and a total of about 8 rings are formed in the control test tubes (Fig. 2(a)). It is

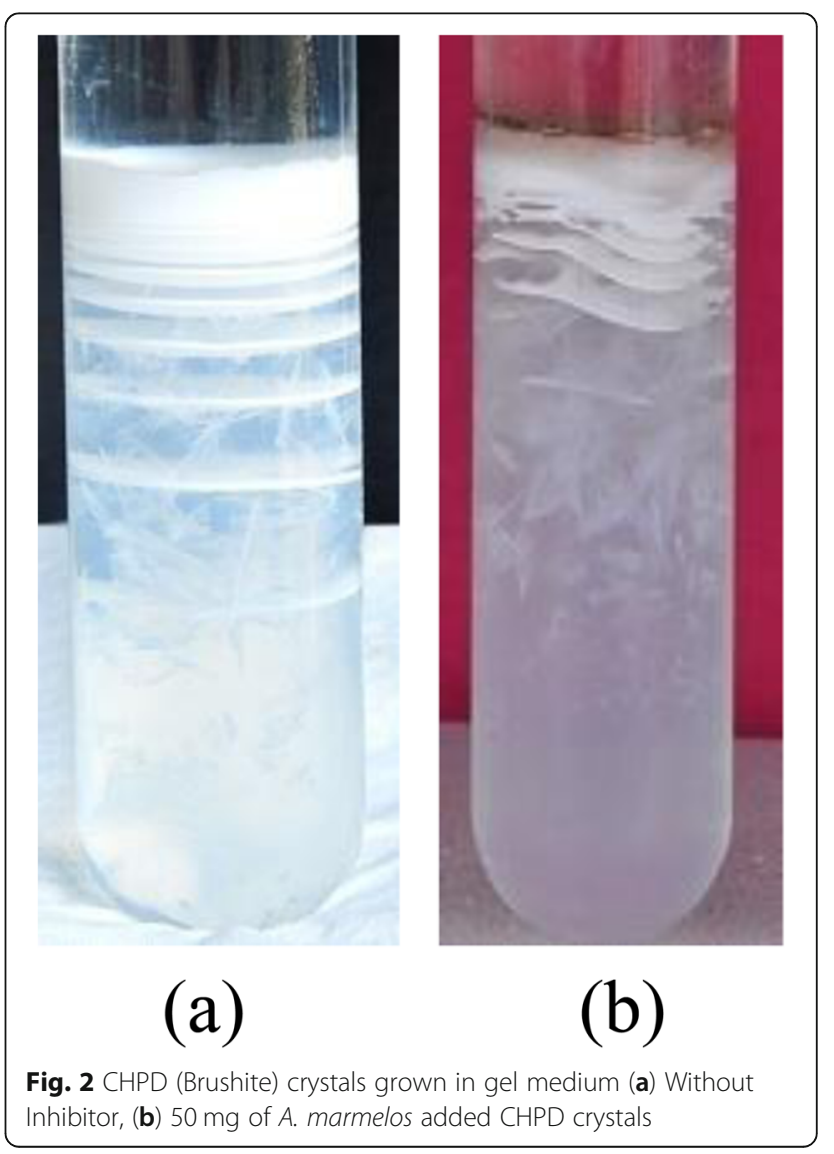


found that the Liesegang rings of CHPD are formed because of the diffusion of ions in the gel medium and shown that the diffusion kinetics is proved by studying the distance $[29,30]$. In due course of time, the crystals are grown where the rings disappeared. The grown crystals of undoped CHPD are shown in Fig. 2(a). Figure 2(b) shows the grown crystals of CHPD by adding $50 \mathrm{mg}$ of $A$. marmelos. Comparing the undoped crystals, the number of crystals grown with A. marmelos is less. The results infer the parameters such as the $\mathrm{pH}$ value, the concentration of reactants, and the column height of the solutions affect the formation of Liesegang rings [31, 32]. On the other hand when we add herbal extracts to the supernatant solution, we observe the less number of Liesegang rings and reduction in length of CHPD crystals grown. This may be due to the changes in the kinetics and diffusion processes and inhibitory effectiveness [33].

The Promotery/Inhibitory effect is judged on the basis of number of crystals grown and total mass of the grown crystals. The same condition is maintained for controlled and test samples.

Figure 3 shows the harvested crystals. Figure 3 (a0) shows undoped CHPD crystals. The crystals are in thin platelet like structure with an average length of $1.2 \mathrm{~cm}$. The rest (a1-a5) show the CHPD crystals added with 10 $\mathrm{mg}, 20 \mathrm{mg}, 30 \mathrm{mg}, 40 \mathrm{mg}$ and $50 \mathrm{mg}$ of $A$.marmelos respectively. The average size of the A. marmelos doped CHPD crystals are less when compare to the undoped CHPD crystals. When the concentration of A. marmelos is increased, the size of the crystals is decreased. At the same time it is reduced furthermore for $50 \mathrm{mg}$ concentration.

Owing to its distinctive ionic structure, CHPD serves as a good model crystal for the study of interactions between additives and crystals. Skiric et al. [34] have summarized as follows:

1. The significance of the molecular structure and additive, i.e., tiny or very large molecule, number of chemical compounds in the molecule and its total charge in the growth of CHPD and other associated crystals. This may be useful for selecting molecules that inhibit the growth of CHPD crystals. One negative charge of glutamate and asparate ions, for instance, has little effect on the CHPD crystal faces, although it can be enhanced by adding more negative groups like $\mathrm{OH}^{-}$

2. The amount of inhibition in a given crystalline face is specified by the structural fit between the organic molecule and the ionic structure of the particular crystal face. This can have an effect on the crystalline faces that are exposed to the solution. The negatively charged small molecules such as citrate ions, interact with the lateral surfaces of the CHPD crystals and hence the crystallization is slowed and the morphology of the crystals is modified.

3. The influence of the exposed hydration layer is seen on the surface of the crystal. In polyaspartic acid, such structural fit exist between the distances of carboxylic groups in the polyaspartic $\beta$ and in the case of CHPD, the distances of the calcium ion across two adjacent layers make up a two-layer $\mathrm{Ca}$ $\mathrm{HPO}_{4}$ below the hydrated layer parallel to the plane (010) [35].

\section{Total mass of the grown CHPD crystals}

Figure 4 shows the histogram depicting total mass of CHPD crystals grown with A. marmelos at $10 \mathrm{mg}, 20$ $\mathrm{mg}, 30 \mathrm{mg}, 40 \mathrm{mg}$ and $50 \mathrm{mg}$ concentrations.

For the cases of $10 \mathrm{mg}$ to $50 \mathrm{mg}$ doped samples, the total mass is decreased than that of undoped. While comparing with the prior concentrations, the total mass for $50 \mathrm{mg}$ concentration is extremely low. The herbal extracts (A. marmelos) contains phytochemicals such as alkaloids, terpenoids, amino acids, carbohydrates, flavonoids and phenols [36] etc. These phytochemicals interact within themselves at low concentrations, and so the penetration decrease and so the total mass. At high concentrations, the each constituent of phytochemicals agglomerate forming an interface between the cations thereby decrease the formation of crystals.

The ANOVA statistical analysis is performed for total mass and listed in Table 1.

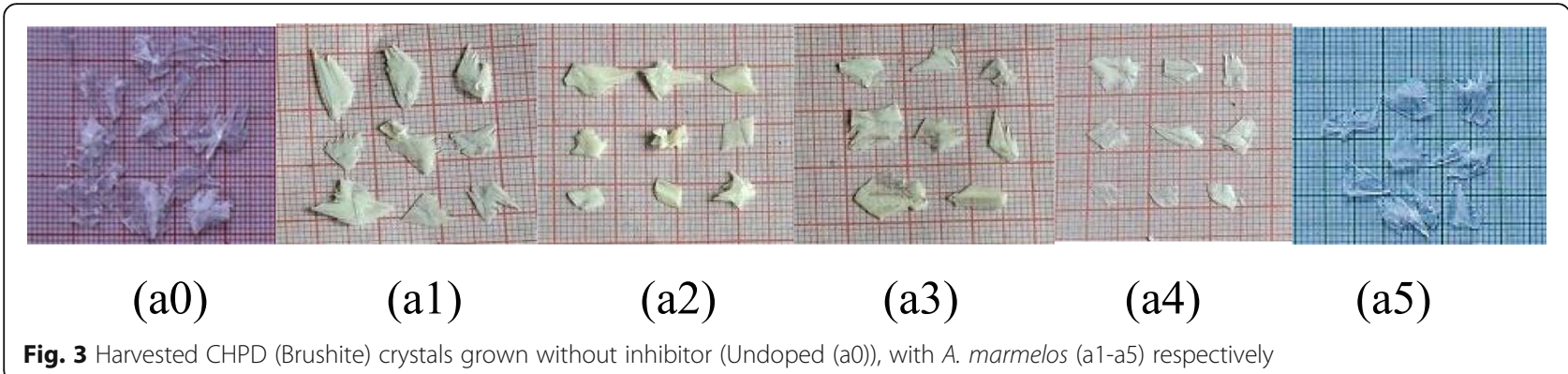




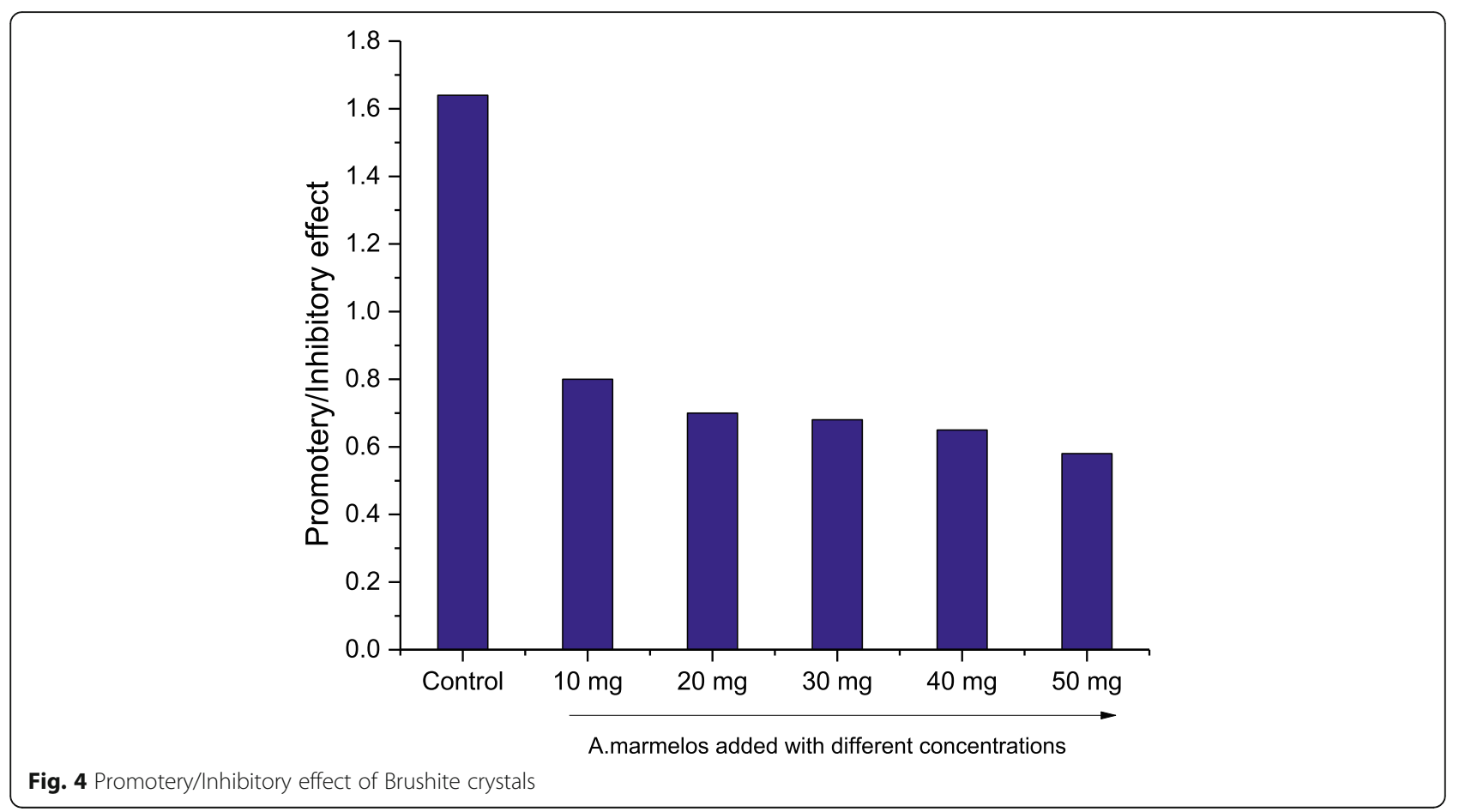

The single factor analysis of variance (ANOVA) followed by Tukeys test is carried out using origin 9 software. It is done to compare the total mass of undoped with doped samples. ANOVA statistical analysis indicates that the variations in the total mass of CHPD with doped samples are highly significant at 0.05 level.

\section{Powder X-ray diffraction}

Powder X-ray diffraction study is performed on grown crystals to identify the phase formation and degree of crystal perfection. Powder X-ray diffraction patterns are recorded in $2 \theta$ steps of 0.05 between $10^{\circ}-80^{\circ}$ using a XPERT-PRO diffractometer with $\mathrm{CuK} \alpha$ radiation at a wavelength of $1.54060 \AA$ operating at $30 \mathrm{~mA}$ and $40 \mathrm{kV}$. The powder X-ray diffractogramfor both undoped and various medicines added CHPD crystals are shown in Figs. 5 and 6 and the $\mathrm{h} \mathrm{k}$ and $\mathrm{l}$ values in brackets are provided.

Table 1 ANOVA statistical analysis of CHPD crystals

\begin{tabular}{llll}
\hline Crystals & Group & Treatments & Mean $(\mathbf{g m}) \pm$ SD \\
\hline Brushite & A & Control (Undoped CHPD) & $1.643 \pm 0.41224$ \\
& B & Control +A. marmelos & $0.80 \pm 0.08101$ \\
& $10 \mathrm{mg}$ & $0.70 \pm 0.08101$ \\
& $20 \mathrm{mg}$ & $0.68 \pm 0.08101$ \\
& $30 \mathrm{mg}$ & $0.65 \pm 0.08101$ \\
& $40 \mathrm{mg}$ & $0.58 \pm 0.08101$ \\
& $50 \mathrm{mg}$ & \\
\hline
\end{tabular}

The XRD pattern of undoped CHPD crystals (Fig. 5) show prominent peak at $2 \theta=11.75^{\circ}$ which corresponds to the $\left(\begin{array}{lll}0 & 2 & 0\end{array}\right)$ plane and the other peaks observed at $2 \theta=21.00^{\circ}, 23.47^{\circ}, 29.32^{\circ}, 30.53^{\circ}, 34.19^{\circ}, 35.60^{\circ}, 37.10^{\circ}$, $39.69^{\circ}, 41.47^{\circ}, 42.27^{\circ}, 45.42^{\circ}, 47.90^{\circ}, 48.53^{\circ}, \quad 50.24^{\circ}$, $53.59^{\circ}, 56.97^{\circ}, 60.92^{\circ}$ and $74.97^{\circ}$ belongs to (1 211$)$, ( $\begin{array}{ll}0 & 3\end{array}$ 1), (1 4-1), (1 2 1), (1 5 0), (0 6 0), (2 2-2), (1 6-1), (1 5-2), (2 4 0), (1 2-3), (0 8 0), (0 6 2), (2 6 0), (3 4-1), (0 9 1), (2 8-2) and (3 8-3) reflections, respectively, of monoclinic structure of CHPD (JCPDS No. 72-0713). Compared to undoped CHPD crystals, the intensity of $(0$ 20 ) peak increases for the doped crystals. This results in a decrease of peak intensity of all the remaining peaks. The $\left(\begin{array}{lll}0 & 2 & 0\end{array}\right)$ peak appears with maximum intensity in undoped CHPD and medicines added CHPD crystals. The higher intensities of $\left(\begin{array}{lll}0 & 2 & 0\end{array}\right)$ plane is a feature of typical deviation from an isotropic orientation of crystallite grains. The higher the number of plate like grains in the sample, the higher the fraction of the $\left(\begin{array}{lll}0 & 2 & 0\end{array}\right)$ planes which are aligned along the specimen surface [34]. The highly resolved peaks at specific $2 \theta$ Bragg angles in the crystals indicate the crystalline nature of the grown crystals. The software CellCalc is used to calculate lattice parameters and is tabulated in Table 2. The crystallographic parameters obtained are well correlated with data available in the literature (JCPDS No [72-0713]). The changes in the lattice parameters and unit cell volume of doped samples may be attributed to the incorporation of added medicines in the host of CHPD crystal. 


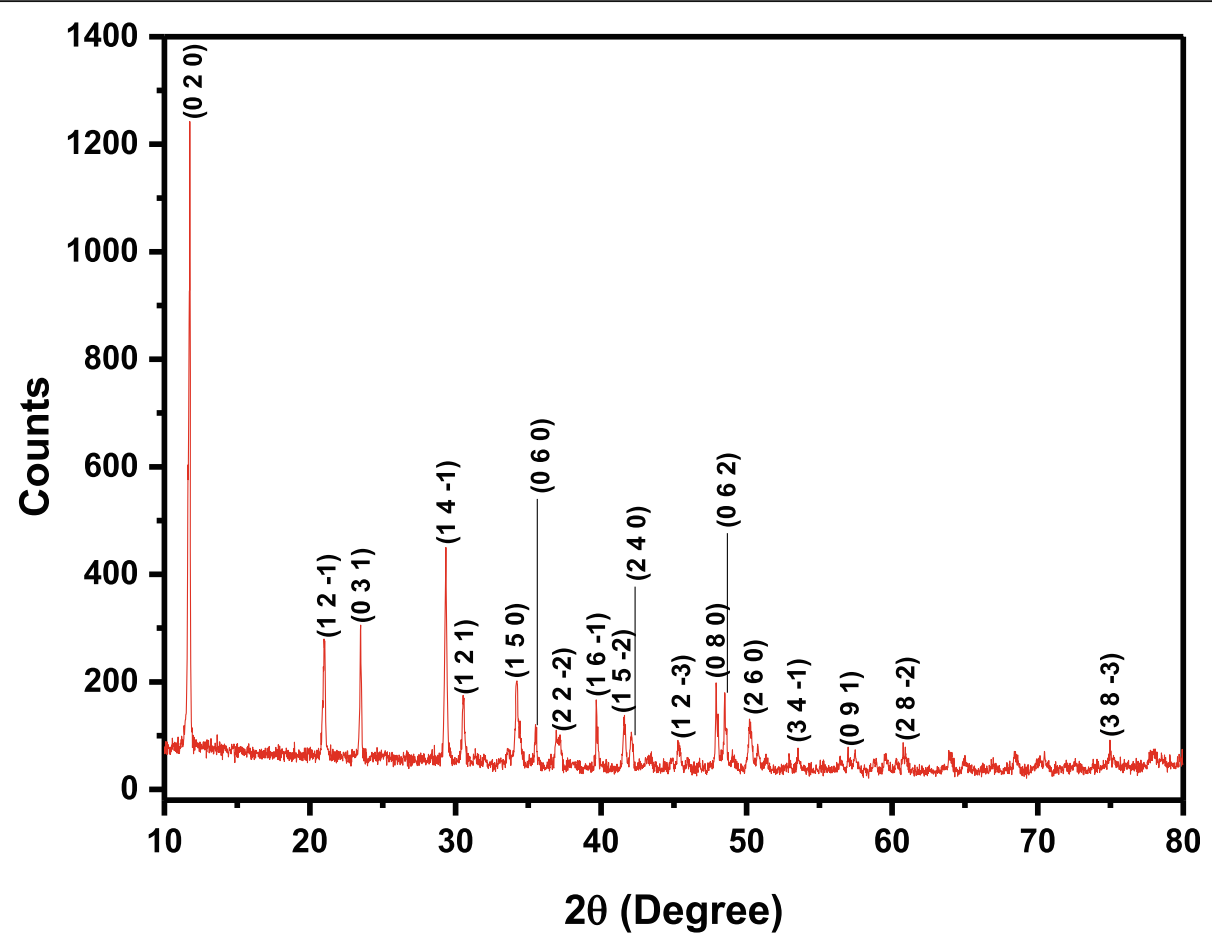

Fig. 5 Powder XRD spectrum of undoped CHPD crystal

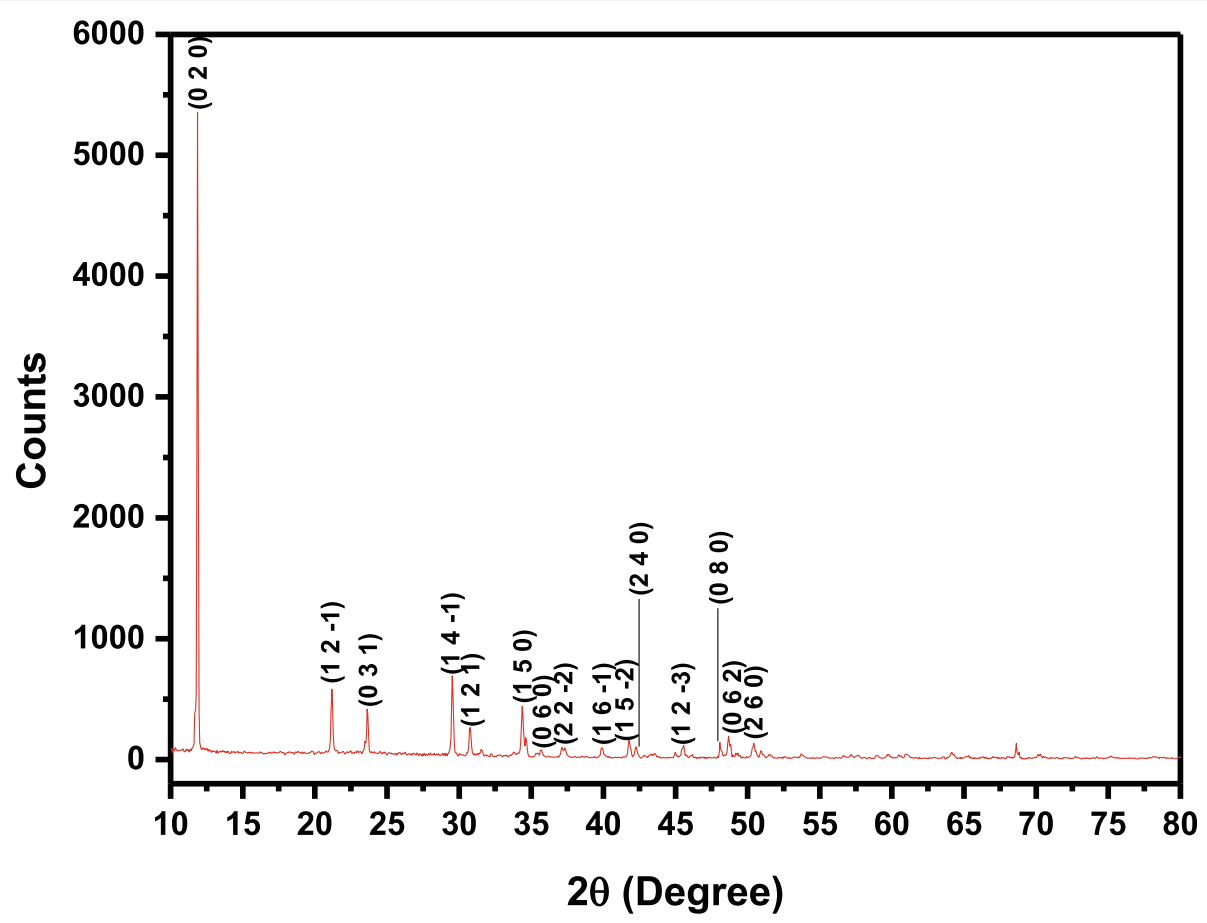

Fig. 6 Powder XRD spectrum of $50 \mathrm{mg}$ A. marmelos added CHPD crystal 
Table 2 Unit cell parameters, Unit cell volume $(V)$ and Angle $(\beta)$ for undoped and A. marmelos added CHPD crystals

\begin{tabular}{|c|c|c|c|c|c|}
\hline \multirow[t]{2}{*}{ Samples } & \multicolumn{3}{|c|}{ Unit cell parameters } & \multirow{2}{*}{$\begin{array}{l}\text { Unit } \\
\text { cell } \\
\text { volume } \\
\text { V } \\
(\AA ̊ 丿)\end{array}$} & \multirow{2}{*}{$\begin{array}{l}\text { Angle } \\
\left(\alpha=\gamma=90^{\circ}\right.\end{array}$} \\
\hline & $\begin{array}{l}\mathrm{a} \\
(\AA)\end{array}$ & $\begin{array}{l}\text { b } \\
\text { (Å) }\end{array}$ & $\begin{array}{l}\mathrm{c} \\
(\AA ̊)\end{array}$ & & \\
\hline Undoped CHPD & 5.87390 & 15.18049 & 6.27126 & 497.474 & $\beta=117.175$ \\
\hline CHPD: $50 \mathrm{mg}$ A. marmelos & 5.81243 & 15.09959 & 6.23185 & 489.266 & $\beta=116.549$ \\
\hline
\end{tabular}

\section{Crystallite size}

The crystallite size of the grown crystals is estimated from the Scherrer equation [37],

$$
\mathrm{D}=\frac{\mathrm{K} \lambda}{\beta \cos \theta}
$$

Where $\mathrm{D}$ is the crystallite size, $\mathrm{K}(=0.89)$ is the constant, $\lambda$ is the wavelength of the X-rays $(\lambda=0.54060 \AA$ for $\mathrm{CuK} \alpha$ radiation), $\beta$ is the full width at half maximum value and $\theta$ is the Bragg diffraction angle.

\section{Microstrain}

The microstrain is calculated using the following relation [38].

$$
\varepsilon=\frac{\beta \cos \theta}{4}
$$

\section{Dislocation density}

A dislocation is an imperfection in a crystal associated with the misregistry of the lattice in one part of the crystal with that in another part $[38,39]$.

The dislocation density $(\delta)$ is evaluated by the formula [40],

$$
\delta=\frac{1}{D^{2}}
$$

\section{Stacking fault probability (a)}

The stacking fault probability $\alpha$ is the fraction of layers undergoing stacking sequence faults in a given crystal and hence one fault is expected to be found in $1 / \alpha$ layers. The stacking fault probabilities are calculated from the shift of the X-ray line of the crystal with reference (JCPDS No: 72-0713 \& 77-2303), using the relation between the stacking fault probability $\alpha$ and the peak shift $\Delta(2 \theta)$ [38].

$$
\alpha=\left[\frac{2 \pi^{2}}{45 \sqrt{3} \tan \theta}\right] \Delta(2 \theta)
$$

The Microstructural properties of the grown crystals calculated from the above formulas are given in Table 3.

The crystallite size, microstrain, Dislocation density and stacking fault probability of undoped CHPD and $A$. marmelos added CHPD crystals are shown in Table 3. The crystallite size of the samples is determined by employing Debye Scherrer's equation. The crystallite size of undoped CHPD is around $51 \mathrm{~nm}$. On doping with $A$. marmelos, the crystallite sizes are found to decrease. This is probably due to the growth inhibition. The dislocation density of the doped crystals increases comparing with the undoped CHPD. This may be due to the piling up of atoms one over the other. This in turn deforms the crystal structure and result into fracture due to brittleness. Thus the crystal formation is inhibited. The stacking fault probability is found to increase on doping, and no major changes are observed. Also it is observed that the Microstructural parameters dislocation density and microstrain depend upon crystallite sizes.

\section{Fourier transform infrared spectroscopy}

The structural studies of Calcium Hydrogen Phosphate Dihydrate crystals by IR spectra show various absorption bands which are characteristics of different vibrational modes. The FTIR spectra of undoped CHPD and $50 \mathrm{mg}$ A. marmelos are shown in Fig. 7 and 8 and functional groups are mentioned in Table 4.

FTIR spectrum of undoped Calcium Hydrogen Phos-

\begin{tabular}{|c|c|c|c|c|}
\hline Samples & Crystallite size $(\mathrm{nm})$ & Micro strain $(\varepsilon)$ & $\begin{array}{l}\text { Dislocation density } \\
\delta \times 10^{14} \text { lines } / \mathrm{m}^{2}\end{array}$ & $\begin{array}{l}\text { Stacking fault probability } \\
\text { (a) }\end{array}$ \\
\hline Undoped CHPD & 51 & 1.69712 & 3.84467 & 0.03331 \\
\hline CHPD: $50 \mathrm{mg}$ of $A$. marmelos & 47 & 0.85691 & 4.52693 & 0.09896 \\
\hline
\end{tabular}
phate Dihydrate (Fig. 7) show the absorption peaks at wavenumbers range of $3162.08 \mathrm{~cm}^{-1}, 3277.8 \mathrm{~cm}^{-1}$,

Table 3 Microstructural parameters of undoped and A. marmelos added CHPD crystals 


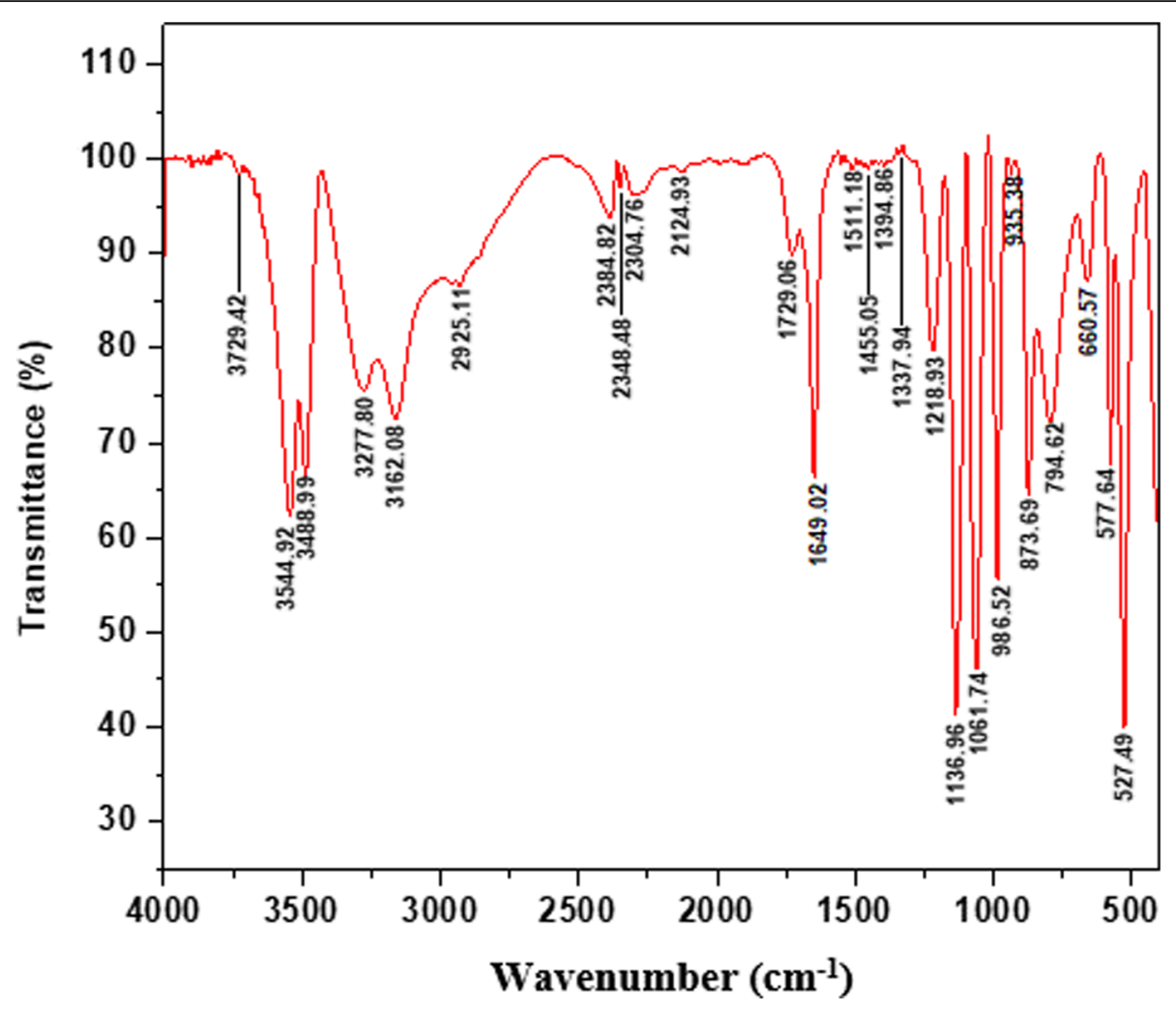

Fig. 7 FTIR spectrum of undoped CHPD crystal

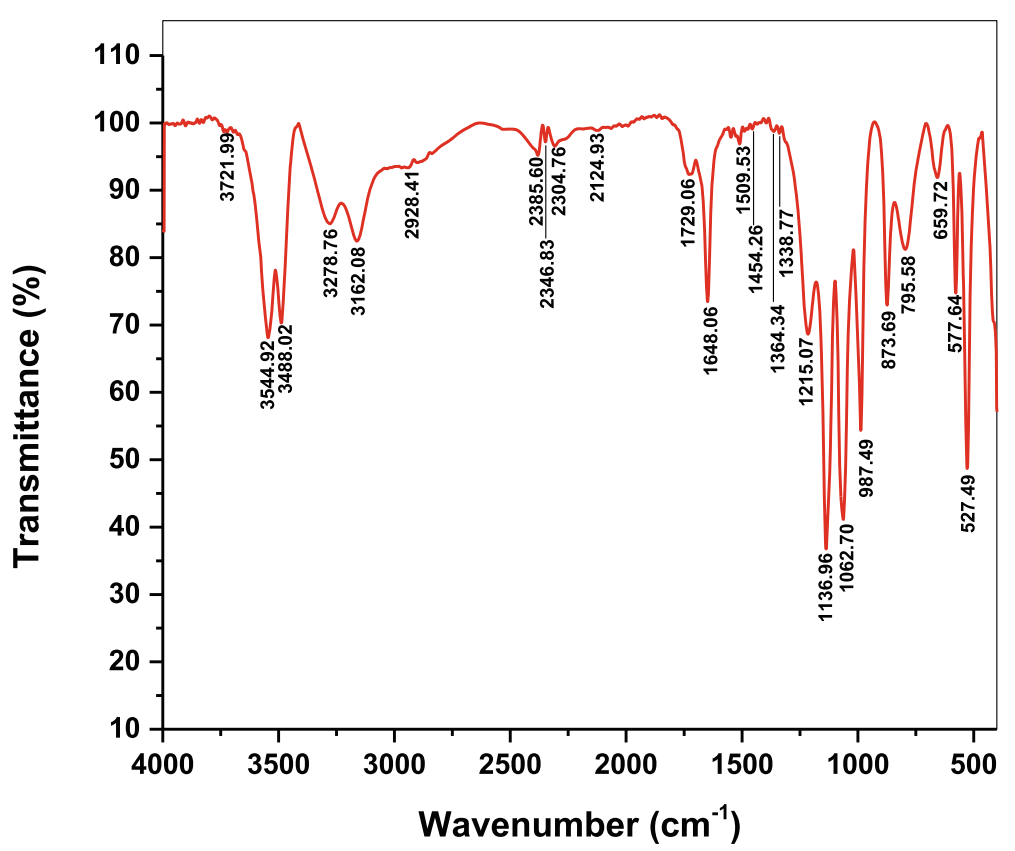

Fig. 8 FTIR spectrum of $50 \mathrm{mg}$ A. marmelos added CHPD crystal 
Table 4 Band Assignments and absorption bands of undoped and A. marmelos added CHPD crystals

\begin{tabular}{|c|c|c|c|}
\hline \multirow[t]{2}{*}{ SI. No } & \multicolumn{2}{|c|}{ Observed IR frequencies wavenumbers $\left(\mathrm{cm}^{-1}\right)$} & \multirow[t]{2}{*}{ Band Assignments } \\
\hline & Undoped CHPD & CHPD: $50 \mathrm{mg}$ A. marmelos & \\
\hline 1 & 3729.42 & 3721.99 & Weakly $\mathrm{H}$ bonded $\mathrm{OH}$ vibrations \\
\hline 2 & 3544.92 & 3544.92 & Weakly $\mathrm{H}$ bonded $\mathrm{OH}$ vibrations \\
\hline 3 & 3488.99 & 3488.02 & Weakly $\mathrm{H}$ bonded $\mathrm{OH}$ vibrations \\
\hline 4 & 3277.8 & 3278.76 & Weakly $\mathrm{H}$ bonded $\mathrm{OH}$ vibrations \\
\hline 5 & 3162.08 & 3162.08 & Weakly $\mathrm{H}$ bonded $\mathrm{OH}$ vibrations \\
\hline 6 & 2925.11 & 2928.41 & OH stretching vibrations \\
\hline 7 & 2384.82 & 2385.6 & Weak absorption $\mathrm{HPO}_{4}{ }^{2-}$ \\
\hline 8 & 2348.48 & 2346.83 & PO-H symmetric stretching vibrations \\
\hline 9 & 2304.76 & 2304.76 & $\mathrm{O}=\mathrm{P}-\mathrm{OH}$ Stretching vibrations \\
\hline 10 & 2124.93 & 2124.93 & $\mathrm{O}=\mathrm{P}-\mathrm{OH}$ Stretching vibrations \\
\hline 11 & 1729.06 & 1729.06 & Weak absorption $\mathrm{HPO}_{4}{ }^{2-}$ \\
\hline 12 & 1649.02 & 1648.06 & $\mathrm{H}-\mathrm{O}-\mathrm{H}$ Symmetric bending vibrations \\
\hline 13 & 1511.18 & 1509.53 & $\mathrm{P}=\mathrm{O}$ stretching vibrations \\
\hline 14 & 1455.05 & 1454.26 & $\mathrm{P}=\mathrm{O}$ stretching vibrations \\
\hline 15 & 1394.86 & 1364.34 & $\mathrm{P}=\mathrm{O}$ asymmetric stretching vibrations \\
\hline 16 & 1337.94 & 1338.77 & $\mathrm{P}=\mathrm{O}$ asymmetric stretching vibrations \\
\hline 17 & 1218.93 & 1215.07 & $\mathrm{PO}_{4} \mathrm{P}=\mathrm{O}$ associated Stretching vibrations \\
\hline 18 & 1136.96 & 1136.96 & $\mathrm{PO}_{4} \mathrm{P}=\mathrm{O}$ associated Stretching vibrations \\
\hline 19 & 1061.74 & 1062.7 & $\mathrm{P}=\mathrm{O}$ Stretching vibrations \\
\hline 20 & 986.52 & 987.49 & P-O-P asymmetric stretching bond \\
\hline 21 & 935.38 & - & $\mathrm{P}-\mathrm{OH}$ stretching vibrations \\
\hline 22 & 873.69 & 873.69 & P-O-P asymmetric stretching bond \\
\hline 23 & 794.62 & 795.58 & P-O-P asymmetric stretching bond \\
\hline 24 & 660.57 & 656.72 & $(\mathrm{H}-\mathrm{O}-) \mathrm{P}=\mathrm{O}$ bond (strong absorption) acid phosphates \\
\hline 25 & 577.64 & 577.64 & ( $\mathrm{H}-\mathrm{O}-) \mathrm{P}=\mathrm{O}$ bond (strong absorption) acid phosphates \\
\hline 26 & 527.49 & 527.49 & $(\mathrm{H}-\mathrm{O}-) \mathrm{P}=\mathrm{O}$ bond (strong absorption) acid phosphates \\
\hline
\end{tabular}

$3488.99 \mathrm{~cm}^{-1}, 3544.92 \mathrm{~cm}^{-1}$ and $3729.42 \mathrm{~cm}^{-1}$ are attributed to intermolecular and weakly $\mathrm{H}$ bonded $\mathrm{OH}$ because of water of crystallization [41, 42]. The characteristic peak at $2925.11 \mathrm{~cm}^{-1}$ is due to $\mathrm{OH}$ stretching vibrations of water [43] and the $\mathrm{HPO}_{4}{ }^{2-}$ weak absorption bands [30] is observed at $2384.82 \mathrm{~cm}^{-1}$ and $1729.06 \mathrm{~cm}^{-1}$. The band at $2348.48 \mathrm{~cm}^{-1}$ is attributed to PO-H symmetric stretching vibrations [44]. Two bands are observed due to $\mathrm{O}=\mathrm{P}-\mathrm{OH}$ stretching vibrations [45] of $\mathrm{HPO}_{4}{ }^{2-}$ near $2124.93 \mathrm{~cm}^{-1}$, $2304.76 \mathrm{~cm}^{-} 1$. An absorption band at $1649.02 \mathrm{~cm}^{-1}$ is occurred due to $\mathrm{H}-\mathrm{O}-\mathrm{H}$ symmetric bending vibrations [46] The absorption peak near $1511.18 \mathrm{~cm}^{-1}, 1455.08 \mathrm{~cm}^{-1}$ and $1061.74 \mathrm{~cm}^{-1}$ are assigned due to $\mathrm{P}=\mathrm{O}$ stretching vibrations [29, 47]. The absorption takes place around $1394.86 \mathrm{~cm}^{-1}$ and $1337.94 \mathrm{~cm}^{-1}$ are due to $\mathrm{P}=\mathrm{O}$ asymmetric stretching vibrations [44]. The peaks about at 1218.93 $\mathrm{cm}^{-1}$ and $1136.96 \mathrm{~cm}^{-1}$ are occurred due to $\mathrm{P}=\mathrm{O}$ associated stretching vibrations of $\mathrm{PO}_{4}$, while peaks at wavenumbers $986.52 \mathrm{~cm}^{-1}, 873.69 \mathrm{~cm}^{-1}$ and $794.62 \mathrm{~cm}^{-1}$ are due to P-O-P asymmetric stretching vibrations [29, 42]. The strong absorption peaks of acid phosphates [29, 48] lie at different wavenumbers of $660.57 \mathrm{~cm}^{-1}, 577.64$ $\mathrm{cm}^{-1}$ and $527.49 \mathrm{~cm}^{-1}$.

By comparing the FTIR spectra of undoped CHPD and $A$. marmelos added CHPD, we determined that the foremost distinction amongst them is the disappearance of the peak encountered at $935.38 \mathrm{~cm}^{-1}$ in the $A$. marmelos added sample (Table 4) corresponding to $\mathrm{P}-\mathrm{OH}$ stretching vibrations. The leaf extracts of $A$. marmelos contains phytochemicals like alkaloids, flavonoids, phenols, saponins, carbohydrates, protein, phytosterol, tannins, glycosides, phenolic compounds, cardiac glycosides [36]. These phytochemicals are rich in polar groups which may interact with phosphate ion in CHPD leading to the disappearance of $\mathrm{P}-\mathrm{O}$ symmetric stretching vibrations respectively. Moreover, slight shifting in FTIR 


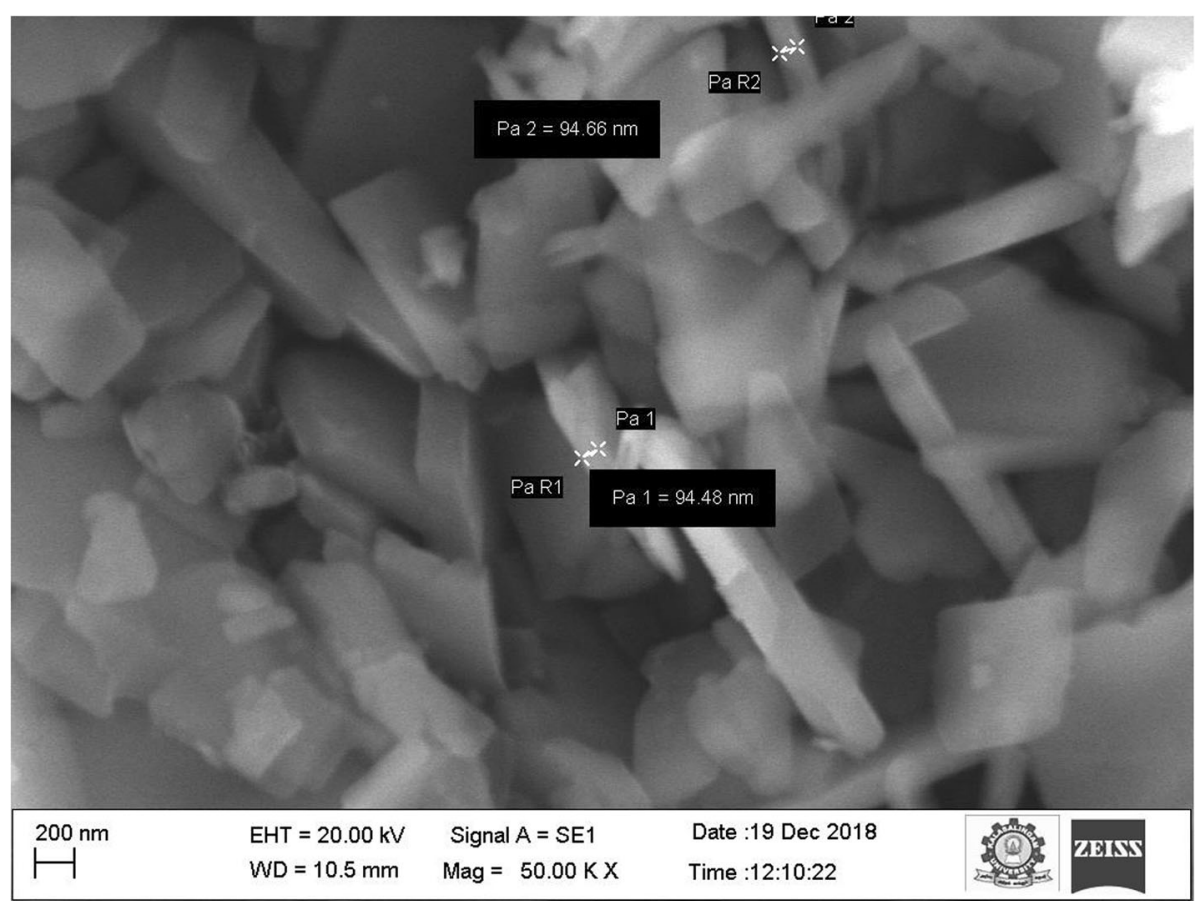

Fig. 9 SEM micrograph of undoped CHPD crystal

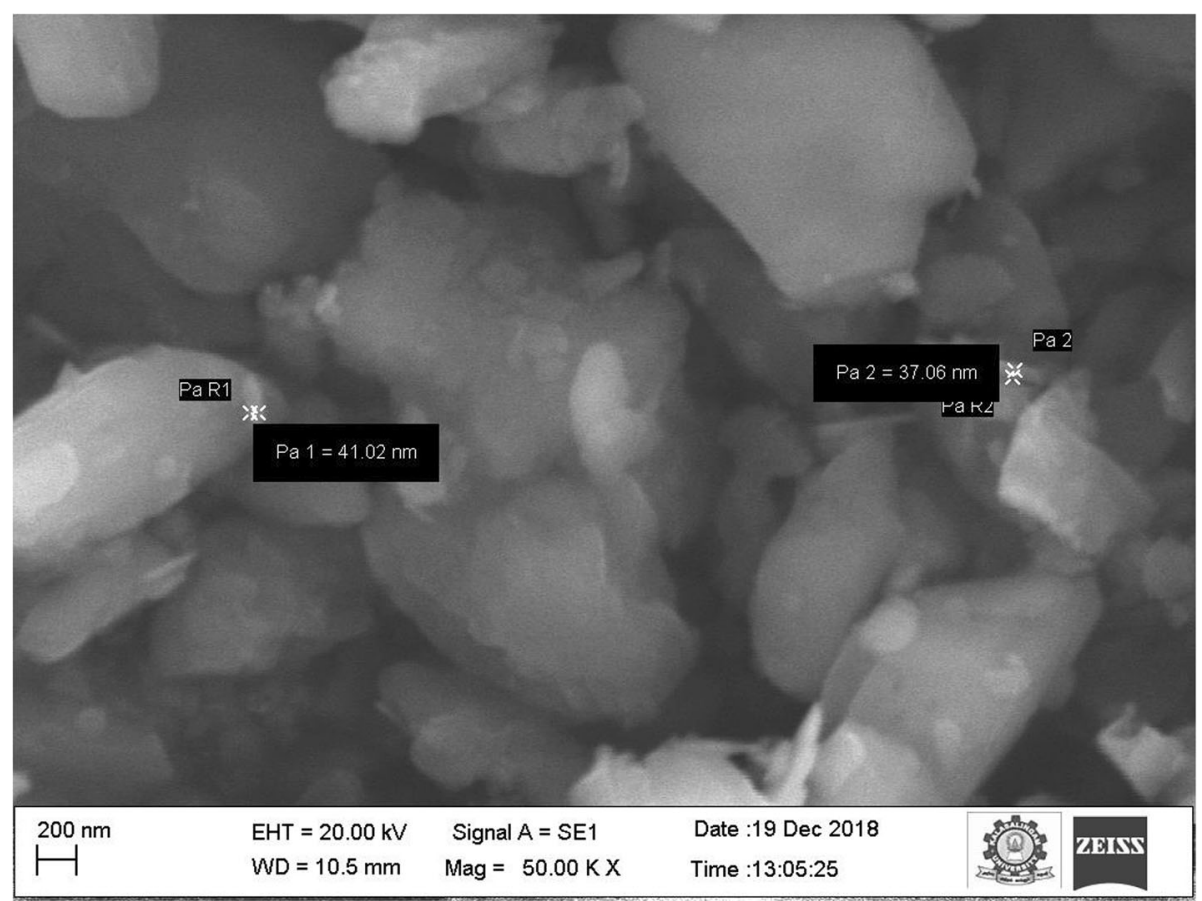

Fig. 10 SEM micrograph of $50 \mathrm{mg}$ A. marmelos added CHPD crystal 


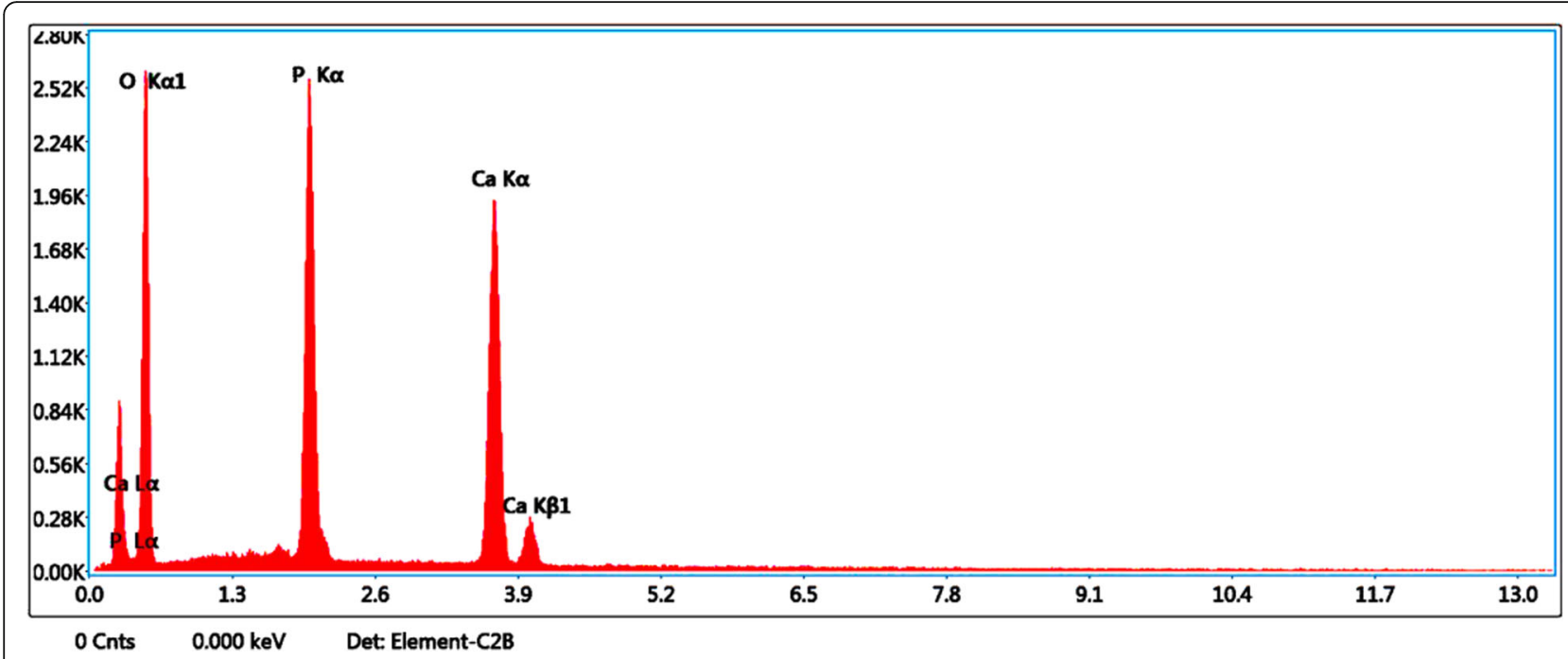

Fig. 11 EDAX spectrum of undoped CHPD crystal

spectra of doped samples suggests the encapsulation of A. marmelos.

\section{Scanning Electron microscopy}

Particle size and Surface morphology of the grown crystals are revealed by scanning-electron microscopy (SEM Model ZEISS EVO 18). The scanning electron micrographs of the samples, undoped CHPD and $50 \mathrm{mg} A$. marmelos added CHPD crystals are shown in Figs. 9 and 10.

Figure 9 illustrates SEM photograph of undoped CHPD crystals. Plate like structure is observed [15]. The particle size of undoped CHPD calculated using SEM picture is around $94 \mathrm{~nm}$. The SEM image of the $50 \mathrm{mg}$ A. marmelos added CHPD crystals is shown in Fig. 10. Particles agglomerate and are in spherical shape. Particle size is in the range of $30-50 \mathrm{~nm}$.

The SEM images of the undoped and A. marmelos added CHPD crystals show difference in their morphologies. The undoped CHPD crystals shows needle and platelets shaped morphology, whereas $50 \mathrm{mg}$ A. marmelos added CHPD, we have the particles agglomerated and are in spherical shape. The growth morphology of CHPD crystals is typically in the form of thin plates with prominent $\left(\begin{array}{lll}0 & 2 & 0\end{array}\right)$ plane. The monoclinic unit cell of CHPD consists alternating bi-layers of calcium, hydrogen phosphate ion and a layer of water molecules

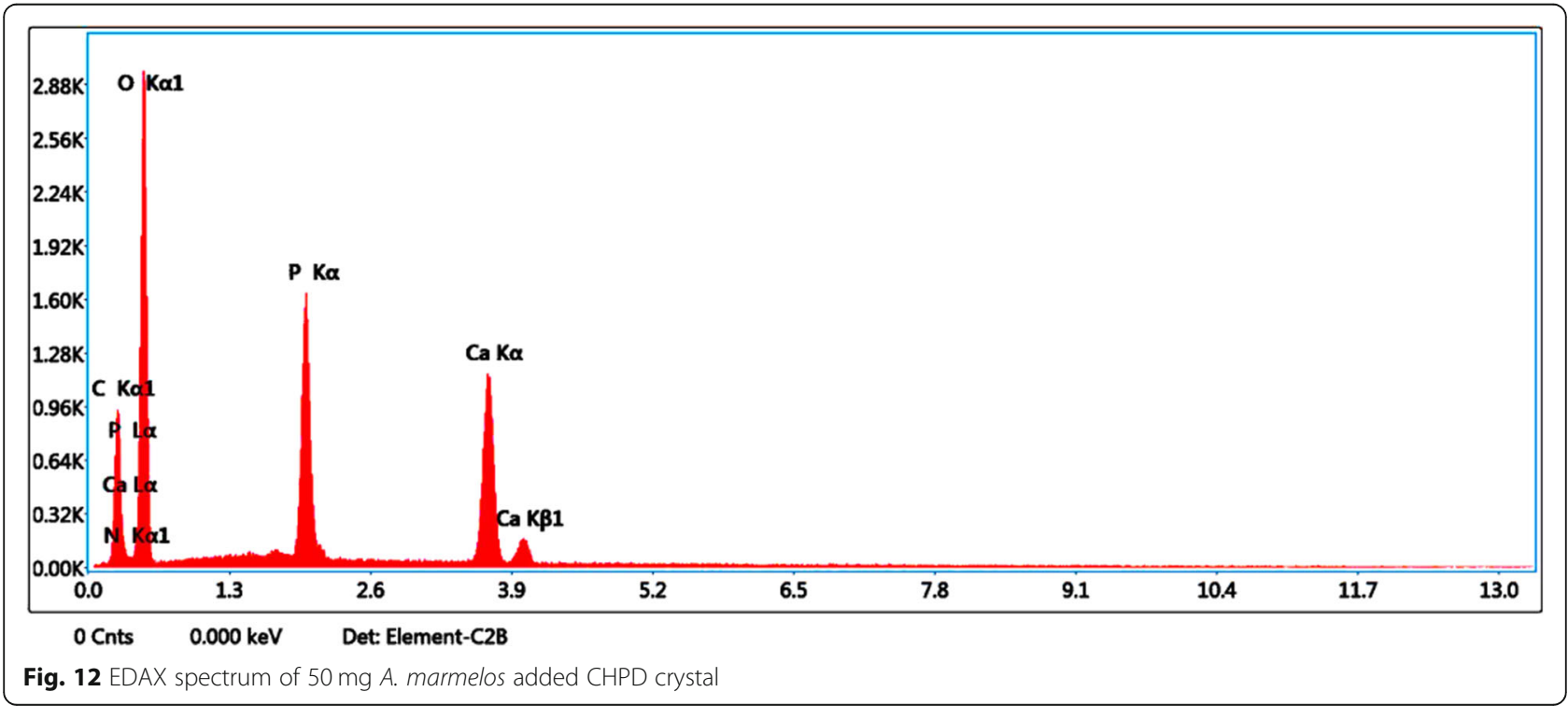


oriented parallel to the $\left(\begin{array}{lll}0 & 2 & 0\end{array}\right)$ plane. As the bi-layers of water molecules are exposed at the surface of $\left(\begin{array}{lll}0 & 2 & 0\end{array}\right)$ face, the surface bound water can form bonds with molecules in the growth medium $[49,50]$. The thin layer of water molecules on the surface of the CHPD may form bonds with the phytochemicals of the A. marmelos extract, thus weakening the ionic nature of the CHPD and leading to the structural modification of the doped crystals into tiny units. The reduction in platelet shape can be attributed to the influence of added extracts onto the CHPD crystal formation altering the growth kinetics of the platelets $[49,51,52]$. The decrease in particle size of medicines added crystals may be due to the inhibition of the grain growth.

\section{Energy dispersive $\mathrm{X}$-ray analysis}

In order to study the elemental composition of undoped and A. marmelos added CHPD crystals, qualitative and quantitative analysis is performed by energy dispersive $\mathrm{X}$-ray analysis (EDAX) using dispersive spectrometer (AMETEK EDAX) attached to the scanning electron microscope. The spectrum obtained from EDAX analysis of undoped CHPD and $50 \mathrm{mg}$ A. marmelos added CHPD crystals is shown in Figs. 11 and 12 and the average atomic and weight percentage of individual elements is given in Tables 5 and 6 .

EDAX pattern of undoped CHPD (Fig. 11) shows the presence of elements such as Calcium, Phosphorus and Oxygen present in the grown crystal. This clearly indicates that the crystals are of Calcium Hydrogen Phosphate Dihydrate indeed. The higher peak of $\mathrm{Ca}, \mathrm{P}$ and $\mathrm{O}$ shows that the more concentrated the element are in the specimen. The $\mathrm{Ca} / \mathrm{P}$ ratio of undoped $\mathrm{CHPD}$ crystal if found as 1.08 , which is closely associated with the actual value of 1 according to the chemical formula [53]. Similarly EDAX pattern of $50 \mathrm{mg}$ A. marmelos added CHPD crystal is shown in Fig. 12. The spectra corresponding to $50 \mathrm{mg}$ A. marmelos added CHPD also show peaks corresponding to all major elements $\mathrm{Ca}, \mathrm{P}$ and $\mathrm{O}$. The $\mathrm{Ca} / \mathrm{P}$ ratio of crystals grown with $50 \mathrm{mg}$ A. marmelos is found as 1.03 .

\section{Conclusion}

The effect of $A$. marmelos on the growth of brushite crystals is examined in vitro. The present study reveals that the herbal extracts of $A$. marmelos inhibit the growth of brushite crystals. It is observed that the

Table 5 EDAX data for undoped CHPD crystal

\begin{tabular}{lll}
\hline Elements & Weight \% & Atomic \% \\
\hline O K & 55.5 & 73.6 \\
P K & 18.5 & 12.7 \\
Ca K & 26.0 & 13.8 \\
\hline
\end{tabular}

Table 6 EDAX data for $50 \mathrm{mg}$ A. marmelos added CHPD crystal

\begin{tabular}{lll}
\hline Elements & Weight \% & Atomic \% \\
\hline C K & 17.1 & 24.8 \\
N K & 1.5 & 1.9 \\
O K & 55.6 & 60.7 \\
P K & 11.0 & 6.2 \\
CaK & 14.8 & 6.5 \\
\hline
\end{tabular}

incorporation of $A$. marmelos caused a decrease in the number of grown brushite crystals and their average size. Powder X-ray diffraction exhibit monoclinic crystal structure and the lattice parameters are in good agreement with the reported values. Also it confirms the incorporation of additional ions in the A. marmelos leaf extracts into the host of CHPD. FTIR confirms the presence of functional groups. SEM shows the morphological changes in the treated crystals. The SEM micrograph of crystals grown in the presence of A. marmelos shows reduction in the grain size with addition of A. marmelos as compared with pure CHPD crystals. EDAX confirms the presence of required elements. From the above observed results, the intake of $A$. marmelos is good for diabetic patients as it reduces the growth of urolithiasis. However, further in vivo studies are needed to evaluate its potential antiurolithiatic activity.

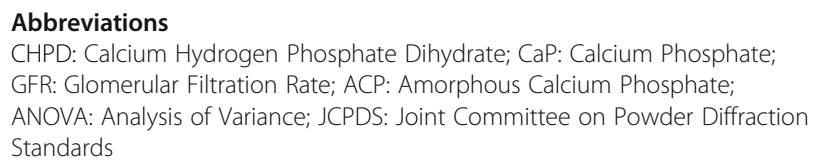

\section{Acknowledgements}

The authors are thankful to Department of Physics (DST-FIST), S.T. Hindu College, Nagercoil for providing facilities for the completion of this work.

\section{Authors' contributions}

GA planned the study, designed the experiments and drafted the manuscript. RM participated in the preparation of herbal extracts and interpretation of results. THF supervised the project and reviewed the manuscript. RR and GR involved in discussing the concepts. All authors read and approved the final manuscript.

Funding

Not Applicable

\section{Availability of data and materials}

The datasets supporting the conclusions of this article are included within the article

\section{Declarations}

Ethics approval and consent to participate Not Applicable

Consent for publication

Not Applicable

Competing interests

GA, RM, THF, RR and GR declare that they have no competing interests. 


\section{Author details}

'Physics Research Centre, S.T. Hindu College, Nagercoil, Tamil Nadu 629002 , India. ${ }^{2}$ Department of Botany, S.T. Hindu College, Nagercoil, Tamil Nadu 629 002, India. ${ }^{3}$ Department of Chemistry, The Madura College, Vidhya Nagar, Madurai, Tamil Nadu 625 011, India. ${ }^{4}$ Department of Zoology, Pioneer Kumaraswamy College, Nagercoil, Tamil Nadu 629 003, India.

\section{Received: 22 July 2020 Accepted: 26 April 2021}

\section{Published online: 07 May 2021}

\section{References}

1. Fakheriand RJ, Goldfard DS. Ambient temperature as a contributor to kidney stone formation: implications of global warming. Kid Int. 2011;79(11):117885. https://doi.org/10.1038/ki.2011.76.

2. Eisner BH, Sheth S, Herrick B, Pais VM, Sawyer M, Miller N, et al. The effects of ambient temperature, humidity and season of year on urine composition in patients with nephrolithiasis. BJU Int. 2012;1 10:1-4.

3. Rodgers AL. Race, ethnicity and urolithiasis: a critical review. Urolithiasis. 2013;41(2):99-103. https://doi.org/10.1007/s00240-012-0516-9.

4. Trinchieri A. Epidemiological trends in urolithiasis: impact on our health care systems. Urol Res. 2006;34(2):151-6. https://doi.org/10.1007/s00240-005-002 9-x.

5. Kohjimoto Y, Sasaki Y, Iguchi M, Matsumura N, Inagaki T, Hara I. Association of Metabolic Syndrome Traits and Severity of kidney stones: results from a Nationwide survey on Urolithiasis in Japan. Am J Kidney Dis. 2013;61(6):9239. https://doi.org/10.1053/.j.jkd.2012.12.028.

6. Coe FL, Evanand A, Worcester E. Kidney stone disease. J Clin Invest. 2005; 115(10):2598-608. https://doi.org/10.1172/JCI26662

7. Parekh BB, Joshi MJ. Crystal growth and dissolution of brushite crystals by different concentrations of citric acid solutions. Indian J Pure AP Phy. 2005; 43:675-8.

8. Thomas WC, Howard JE. Studies on the mineralizing propensity of urine from patients with and without renal calculi. Trans Assoc Am Physicians. 1959;72:181

9. Boyce WH, King JS. Present concepts concerning the origin of matrix and stones. Ann N Y Acad Sci. 1963;104(2):563-78.

10. Tiselius HG. Stone incidence and prevention. Braz J Urol. 2000;26(5):452-62.

11. Miller NL, Evan AP, Lingeman JE. Pathogenesis of renal calculi. Urol Clin N Am. 2007;34(3):295-313.

12. Evan AP. Physiopathology and etiology of stone formation in the kidney and the urinary tract. Pediatr Nephrol. 2010;25(5):831-41. https://doi.org/10.1 007/s00467-009-1116-y

13. National Endocrine and Metabolic Diseases Information Service. Hyperparathyroidism. (NIH Publication No.6-3425). 2006. https://www.niddk. nih.gov/-/media/Files/Endocrine- Diseases/Primary_Hyperparathyroidism_ 508.pdf. Accessed 25 June 2018.

14. National Endocrine and Metabolic Diseases Information Service. Renal Tubular Acidosis. (NIH Publication No. 09-4696). 2008. https://www.niddk. nih.gov/-/media/Files/Kidney-Disease/renaltubularacidosis_508.pdf. Accessed 25 June 2018.

15. Bindhu B, Veluraja K. Medical implications of Syzygium Cumini nut on the growth of Brushite crystals. Natl Acad Sci India Section A Physical Sci. 2018; 89:587-92.

16. Krambeck AE, Handa SE, Evan AP, Lingeman JE. Brushite stone disease as a consequence of lithotripsy. Urol Res. 2010;38(4):293-9. https://doi.org/10.1 007/s00240-010-0289-y.

17. Dhayat NA, Luthi D, Schneider L, Mattmann C, Vogt B, Fuster GD. Distinct phenotype of kidney stone formers with renal phosphate leak. Nephrol Dial Transpl. 2019;34(1):129-37. https://doi.org/10.1093/ndt/gfy170.

18. Xie B, Halter TJ, Borah BM, Nancollas GH. Aggregation of calcium phosphate and oxalate phases in the formation of renal stones. Cryst Growth Des. 2015;15(1):204-11. https://doi.org/10.1021/cg501209h.

19. Abdel-Gawad M, Ali-El-Dein B, Mehta S, Al-Kohlany KM, Elsobky E. A correlation study between macro- and micro-analysis of pediatric urinary calculi. J Pediatr Urol. 2014;10(6):1267-72. https://doi.org/10.1016/j.jpurol.2 014.06.022.

20. Moreira JM, Friedlander JI, Hartman C, Elsamra SE, Smith AD, Okeke Z Differences in 24-hour urine composition between apatite and Brushite stone formers. Urology. 2013;82(4):768-72. https://doi.org/10.1016/j. urology.2013.04.025.
21. Balakumar S, Rajan S, Thirunalasundari T, Jeeva S. Antifungal activity of Aegle marmelos (L.) Correa (Rutaceae) leaf extract on dermatophytes. Asian Pac J Trop Biomed. 2011;1(4):309-12. https://doi.org/10.1016/S2221-1691(11)60049-X.

22. Chopra RN, Verma BS, Chopra IC. Supplement to Glossary of Indian Medicinal Plants. New Delhi: Publications \& Information Directorate; 1969.

23. Nirupama GS, Padmasri G, Vasanthi M. Comparative analysis of phytochemical constituents present in various parts of Aegle marmelos. Asian Pac J Trop Dis. 2012;2:S774-7. https://doi.org/10.1016/S2222-1808(12 )60263-1.

24. Narender T, Sweta S, Tiwari P, Pappi Reddy K, Khaliq T, Prathipati P, et al. Antihyperglycemic and antidyslipidemic agent from Aegle marmelos. Bioorg Med Chem. 2007;17(6):1808-11. https://doi.org/10.1016/j.bmcl.2006.12.037.

25. Karmase A, Birari R, Bhutani KK. Evaluation of anti-obesity effect of Aegle marmelos. Phytomedicine. 2013;20(10):805-12. https://doi.org/10.1016/j. phymed.2013.03.014.

26. Phuwapraisirisan P, Puksasook T, Jong Aramruang J, Kokpol U. Phenylethylcinnamides: a new series of a-glucosidase inhibitors from the leaves of Aegle marmelos. Bioorg Med Chem Lett. 2008;18(18):4956-8. https://doi.org/10.1016/.j.bmcl.2008.08.024.

27. Jethva H. Gel growth: a brief review. Mech Mater Sci Eng. 2017:9:1-7.

28. Patel AR, Venkateswara RA. Crystal growth in gel media. Bull Mater Sci. 1982; 4(5):527-48. https://doi.org/10.1007/BF02824961.

29. Rajendran K, Dale KC. Growth and characterization of calcium hydrogen phosphate dihydrate crystals from single diffusion gel technique. Cryst Res Technol. 2010;45(9):939-45. https://doi.org/10.1002/crat.200900700.

30. Joshi VS, Joshi MJ. FTIR spectroscopic, thermal and growth morphological studies of calcium hydrogen phosphate dihydrate crystals. Cryst Res Technol. 2003;38(9):817-21. https://doi.org/10.1002/crat.200310100.

31. Joseph KC, Joshi MJ. The study of the different parameters affecting Liesegang rings formation during the growth of calcium hydrogen phosphate dihydrate crystals. Indian J Phys. 2002;76A(2):159-63.

32. Joshi VS. Effect of supernatant solutions on the formation of Liesegang rings. Int J Innov. 2016;5(1):1027-31.

33. Joshi VS, Parekh BB, Joshi MJ, Vaidya ADB. Inhibition of the growth of urinary calcium hydrogen phosphate dihydrate crystals with aqueous extracts of Tribulus terrestris and Bergenia Liqulata. Urol Res. 2005;33(2):80-6. https://doi.org/10.1007/s00240-004-0450-6.

34. Sikiric M, Ivancic B, Milat O, Sarig S, Furedi MH. Factors influencing additive interactions with calcium hydrogen phosphate Dihydrate crystals. Langmuir. 2000:16(24):9261-6. https://doi.org/10.1021/la000704m.

35. Joseph KC, Parekh BB, Joshi MJ. Inhibition of growth of urinary type calcium hydrogen phosphate dihydrate crystals by tartaric acid and tamarind. Curr Sci. 2015;88(8):1-7.

36. Asaduzzaman M, Nahar L, Fazley Rabbi M, Hasan M, Khatun A, Tamannaa Z, et al. Phytochemicals, nutritional constituents, anti-bacterial and hypoglycemic activity of Aegle Marmelos Lin. Leaf extract in Alloxan induced diabetic rats. J Nutr Food Sci. 2016:6(4):1-7.

37. Girase KD, Girase ND, Sawant DK, Patil HM, Bhavsar DS. Influence of Zn (II) doping on the structural and optical properties of gel grown Lead iodate crystals. Adv Appl Sci Res. 2011;2(4):233-9.

38. Henry J, Mohanraj K, Sivakumar G. Electrical and optical properties of CZTS thin films prepared by SILAR method. J Asian Ceram Soc. 2016;4(1):81-4. https://doi.org/10.1016/j.jascer.2015.12.003.

39. Thool GS, Singh AK, Singh RS, Gupta A, Susan MABH. Facile synthesis of flat crystal ZnO thin films by solution growth method: a micro-structural investigation. J Saudi Chem Soc. 2014;18(5):712-21. https://doi.org/10.1016/j. jscs.2014.02.005.

40. Muthuselvi C, Dhavachitra M, Pandiarajan S. Growth and characterization of aspirin crystal in the phosphoric acid medium. J Chem Pharm. 2016;8(5): 804-14.

41. Madhurambal G, Subha R, Mojumdar SC. Crystallization and thermal characterization of calcium hydrogen phosphate dihydrate crystals. J Therm Anal Calorim. 2009;96(1):73-6. https://doi.org/10.1007/s10973-008-9841-1.

42. Yuvarani T, Manjula K, Ananda GP. Growth and characterization of calcium hydrogen phosphate Dihydrate crystals influenced by Costus igneus aqueous extract. Int J Pharm Pharm Sci. 2017;9(5):173-8. https://doi.org/1 0.22159/ijpps.2017v9i5.16838

43. Suryawanshi VB, Chaudhari RT. Spectroscopic studies of gel grown zinc doped calcium hydrogen phosphate crystals. AlP Conference Proceedings of the 2nd International Conference on Condensed Matter and Applied Physics. 2018;1953(1): 070025(1)-070025(4). 
44. Trivedi MK, Branton A, Trivedi D, Nayak G, Bairwa K, Jana S. Spectroscopic characterization of disodium hydrogen orthophosphate and sodium nitrate after biofield treatment. J Chromatogr Sep Tech. 2015;6(5):1-5.

45. NIST Chemistry WebBook. http://webbook.nist.gov Accessed 5 July 2018.

46. Dalal PV, Saraf KB. Growth and study of barium oxalate single crystals in agar gel. Bull Mater Sci. 2006;29(5):421-5. https://doi.org/10.1007/BF02914 071

47. Hoffmann G, Veszpremi T, Nagy A. Properties of IR spectra of Phosphorus doped SiO2 films; 1979. p. 176-84.

48. Borah BM, Lakshmi H, Das G. Biomimetic modulation of crystal morphology using gel: from nano to micron-scale architectures. Mater Sci Eng C. 2008; 28(7):1173-82. https://doi.org/10.1016/j.msec.2007.10.059.

49. Curry NA, Jones DW. Crystal structure of brushite, calcium hydrogen orthophosphate dihydrate: a neutron-diffraction investigation. J Chem Soc A. 1971:3725-9. https://doi.org/10.1039/19710003725.

50. Haninen D, Geiger A, Addadi L. Fibronectin adsorption to surfaces of hydrated crystals. An analysis of the importance of bound water in protein substrate interactions. Langmuir. 1993;9(4):1058-65. https://doi.org/10.1021/ la00028a030.

51. Abbona F, Christensson F, Franchini-Angela M, Ludager Madsen HE. Crystal habit and growth conditions of brushite, $\mathrm{CaHPO}_{4} \cdot 2 \mathrm{H}_{2} \mathrm{O}$. J Cryst Growth. 1993;131(3-4):331-46. https://doi.org/10.1016/0022-0248(93)90183-W.

52. Diana K, George KV. Urinary stone formation: Efficacy of seed extract of Ensete superbum (Roxb.) Cheesman on growth inhibition of calcium hydrogen phosphate dihydrate crystals. J Cryst Growth. 2013;363:164-70.

53. Suguna $\mathrm{K}$, Sekar C. Role of strontium on the crystallization of calcium hydrogen phosphate Dihydrate (CHPD). J Minerals Materials Characterization Eng. 2011;10(7):625-36. https://doi.org/10.4236/jmmce.2 011.107048

\section{Publisher's Note}

Springer Nature remains neutral with regard to jurisdictional claims in published maps and institutional affiliations.

\section{Submit your manuscript to a SpringerOpen ${ }^{\circ}$ journal and benefit from:}

- Convenient online submission

- Rigorous peer review

- Open access: articles freely available online

- High visibility within the field

- Retaining the copyright to your article

Submit your next manuscript at $\boldsymbol{\nabla}$ springeropen.com 